\section{A atividade docente à luz de categorias da semântica do agir em relatórios de estágio}

The teaching activity in the light of categories of the
Diana Ribeiro GUIMARÃES (UFPB) diana.rguimaraes@gmail.com

Regina Celi Mendes PEREIRA (UFPE) reginacmps@gmail.com

Recebido em: 30 de maio de 2018. Aceito em: 25 de set. de 2018.
GUIMARÃES, Diana Ribeiro; PEREIRA, Regina Celi Mendes. A atividade docente à luz de categorias da semântica do agir em relatórios de estágio. Entrepalavras, Fortaleza, v. 8, n. 3, p. 84-102, out-dez/2018

Resumo: Os relatórios produzidos pelo graduando para atender às exigências de avaliação, na disciplina de Estágio Supervisionado (ES), após a regência das aulas, são extremamente valiosos, uma vez que materializam, através da ação de linguagem, os diversos desafios enfrentados pelo aluno, durante o processo de experienciar a prática docente, assim como possibilita uma apreciação sobre os elementos que configuram o agir docente, isto é, as razões, as intenções e os recursos mobilizados por esse ator. Tendo isso em vista, elegemos como objetivo deste estudo analisar as categorias da Semântica do Agir e seu entrelaçamento com as modalizações em relatórios de Estágio Supervisionado de formação inicial em ensino de Língua Portuguesa. Para cumprir este objetivo, adotamos uma orientação teórico-metodológica que se pauta nos pressupostos do Interacionismo Sociodiscursivo (BRONCKART, 2012, 2006 2008; MACHADO; BRONCKART, 2009), nas Ciências do Trabalho (AMIGUES, 2004; CLOT, 2007) e na Linguística Aplicada (MOITA LOPES, 2006), para os quais o agir e a linguagem exercem um papel fundamental no desenvolvimento humano. Dentre os resultados obtidos, interpretamos que a prática do ES é de 
extrema valia para os estagiários iniciantes, os quais estão se apropriando do gênero da atividade e constituindo sua identidade profissional, para que possam conhecer de perto a realidade das escolas, onde poderão atuar futuramente, e refletir criticamente sobre os recursos utilizados, sobre as necessárias renormalizações e até sobre o profissional que não deseja ser. Quanto à ordem linguística, constatamos que houve o uso de modalidades pragmáticas, apreciativas e deônticas aliadas à categoria do agir finalidades.

Palavras-chave: Semântica do Agir. Linguagem. Estágio docente. Relatório.

Abstract: The reports produced by the graduating to meet the evaluation requirements, in the subject of Supervised Internship (ES), after the regency of the classes, are extremely valuable, since they materialize, through the action of language, the diverse challenges faced by the student during the process of experiencing teaching practice, as well as making possible an appreciation of the categories of Semantics of Action, that is, the reasons, intentions and resources mobilized by this actor. With this in mind, we chose as objective of this study to analyze the elements of the action and its interweaving with the modifications in Supervised Internship reports of initial training in Portuguese Language Teaching. In order to fulfill this objective, we adopted a theoretical-methodological orientation that is based on the presuppositions of Sociodiscursivo Interacionismo (BRONCKART, 2012, 2006, 2008, MACHADO and BRONCKART, 2009), in the Labor Sciences (AMIGUES, 2004, and CLOT, 2007) and Applied Linguistics (Moita Lopes, 2006), for which action and language play a fundamental role in human development. Among the obtained results, we interpret that the ES practice is extremely valuable for beginning trainees, who are appropriating the activity genre and constituting their professional identity, so that they can know the reality of the schools closely, where they can act in the future, and reflect critically on the resources used, on the necessary renormalizations and, reflect even on the professional who does not want to be. As for the linguistic order, we find that there were the use of pragmatic, appreciative and deontic modalities allied to the category of acting purposes.

Keywords: Semantics of Action. Language. Teaching internship. Reports.

\section{Introdução}

Ensinar, conforme muitos, ideologicamente, já assumiram, não é um dom e sim uma ação que, como em outras profissões, deve ser avaliada como um trabalho que apresenta tanto ações universais, as quais caracterizam o coletivo desta atividade de ensino, quanto ações particulares de professores, renormalizadas, que assinalam o seu estilo profissional. Por isso, temos a importância da disciplina de Estágio Supervisionado (ES) como propulsora para a construção identitária do ser professor, pois o licenciando pode ir se apropriando dos saberes constitutivos dessa prática, ou seja, do "gênero da atividade", ao ter que adentrar em uma sala de aula, observar as aulas de outro professor, em seguida, planejar e elaborar, previamente, uma sequência didática, um plano de aula, pôr em prática o que foi planejado e, posteriormente, escrever um relatório que lhe possibilite refletir sobre tal experiência. Nas palavras de Pimenta \& Lima (2008, p. 111), "ao transitar da universidade para a escola e desta para a universidade, os estagiários podem tecer uma rede de relações, conhecimentos e aprendizagens [...]". 
v. 8 (3)

$84-102$

out-dez

2018

Menezes e Medrado (2013) afirmam que, "enquanto atividade de natureza didática e curricular, o estágio visa ao aprendizado das competências inerentes à atividade profissional, objetivando o desenvolvimento do educando para o trabalho". Portanto, é um momento de grande valor para o licenciando iniciante, o qual poderá vivenciar os constantes desafios do fazer/agir docente, demarcando, assim, uma importante etapa em sua vida profissional, uma vez que pode tornar-se a razão para prosseguimento ou, até mesmo, para desistência da carreira.

Os desafios enfrentados, nesse percurso, muitas vezes, são decorrentes de pesquisas anteriores sobre o agir docente, resultantes da disciplina de ES, com reflexões críticas de teor depreciativo com os envolvidos nas atividades de estágio, em especial, o professor-titular, as quais não contribuíam para a desejada inovação do ensino, e também, na maioria das vezes, não demonstravam o retorno dos resultados obtidos pelos estagiários às instituições escolares. Isso acabou gerando uma fronteira entre a universidade e a prática pedagógica na escola, conforme afirma Telles (2002). Como bem destaca Miranda (2008, p. 16), "não basta observar e/ou denunciar, faz-se necessário enfrentar as situações e construir alternativas de ação. O estágio é, portanto, uma ação educativa e social, uma forma de intervir na realidade".

Os relatórios produzidos, ao final, pelo licenciando, para atender às exigências de avaliação dessa prática, na disciplina de ES, também são de extrema valia, uma vez que materializam, através da ação de linguagem, esses diversos desafios enfrentados pelo graduando, durante o processo de experienciar a prática docente, assim como possibilitam uma apreciação sobre as razões, as intenções e os recursos mobilizados por esse ator. Essa materialização é realizada por meio das modalizações, as quais, segundo Bronckart (2012), configuram linguisticamente a avaliação do conteúdo temático. Essas produções realizadas por professores em formação permitem a criação, em sala de aula, de um espaço confortável para a compreensão dessas experiências de ensino, ou seja, do processo de tornar-se professor (MEDRADO, 2012).

Beltrão e Beltrão (1998, p. 323) definem relatório como

a exposição de ocorrências ou da execução de serviços, ou de fatos de uma administração pública ou privada sendo essa exposição acompanhada, quando necessário, de gráficos, mapas, tabelas, ilustrações. Sua linguagem é factual, no mais das vezes. [...] o relator deve tomar como base um fato real, descrevê-lo cuidadosamente, interpretá-lo e, com base na descrição e na interpretação do fato, apresentar propostas práticas (grifo nosso). 
A interpretação de tal definição nos leva a perceber que a escrita do relatório demanda um posicionamento crítico por parte do professor em formação, ao narrar suas práticas em sala de aula, tendo em vista que é "nele e através dele que temos acesso às representações construídas pelo professor em formação de cenas do trabalho cotidiano da sala de aula" (LEURQUIN, 2013, p. 296). No entanto, nem sempre isso ocorre, e sua escrita acaba se resumindo à mera descrição da experiência, assim como, normalmente, não há um retorno sobre essa escrita, por parte do professor-formador.

Diante das afirmações assinaladas, lançamos como questionamento para este estudo: que categorias da Semiologia/ Semântica do Agir (determinantes externos, motivos, intenções, finalidades, capacidades, recursos utilizados e actantes), atreladas às modalizações, são tematizadas nos relatórios de ES de formação inicial em Língua Portuguesa (LP)? Para isso, elencamos como objetivo analisar as categorias da Semiologia/Semântica do Agir tematizadas em relatórios de ES de formação inicial em LP e seu entrelaçamento com as modalizações, adotando uma orientação teórico-metodológica que se pauta no Interacionismo Sociodiscursivo, doravante ISD, (BRONCKART, 2012, 2006, 2008; MACHADO; BRONCKART, 2009), nas Ciências do Trabalho (AMIGUES, 2004; CLOT, 2007, 2012) e na Linguística Aplicada (MOITA LOPES, 2006), para os quais o agir e a linguagem exercem um papel fundamental no desenvolvimento humano.

Acreditamos que essas informações também permitem visualizar as reconfigurações construídas sobre o agir docente e as "representações construídas pelo agente-produtor", por isso são tão importantes nesse estudo para melhor interpretarmos os êxitos e desafios experienciados no ES.

Os fragmentos dos textos selecionados para a análise do presente estudo foram extraídos de um corpus proveniente de relatórios de estágio produzidos por licenciandos de Letras de uma universidade pública do estado da Paraíba, em Campina Grande, para a disciplina de Estágio Supervisionado IV, no segundo semestre de 2014. A escolha desses relatórios se deve ao fato de a pesquisadora ter sido, nesse momento, a professora-supervisora da disciplina de Língua Portuguesa e por esse ser o último estágio da grade curricular do curso de Letras, no qual os licenciandos já deveriam ter observado, em Estágio Supervisionado III, a turma de Ensino Médio e, agora, seria o momento de atuação e intervenção. Os estagiários desta turma formaram pares e elaboraram 
v. $8(3)$

84-102

out-dez

2018

a sequência didática a ser desenvolvida com os alunos, a partir das orientações da professora-supervisora e, em seguida, colocaram-na em prática. Tendo em vista este contexto, a pesquisa caracteriza-se como qualitativa, de natureza documental e interpretativista.

A fim de cumprirmos o objetivo proposto para este estudo, organizamos nosso texto do seguinte modo: além desta introdução, apresentamos, na próxima seção de desenvolvimento, alguns pressupostos teóricos, ancorados no ISD, na Clínica da Atividade e na LA, que julgamos pertinentes à compreensão do papel revelador que a linguagem assume nesta teoria, ao se pesquisar a atividade docente, bem como os elementos constitutivos da semiologia do agir, que são de grande relevância para respondermos a questão aqui proposta. Em seguida, são analisados os elementos detectados nos relatórios de estágio, produzidos por licenciandos em Letras, seguidos de sucintas conclusões sobre o tema em estudo.

\section{Linguística Aplicada, ISD e Clínica do Trabalho: panorama sobre a relação entre linguagem, desenvolvimento humano e trabalho}

O estudo de Miller (2013) demonstra o quão desafiador é para o pesquisador se enveredar pelo caminho do novo paradigma da pesquisa qualitativa e pela área da Linguística Aplicada Contemporânea, também considerada como "indisciplinar", "transgressiva" (PENNYCOOK, 2006, p. 82)", devido à complexidade das questões sobre as quais, ainda, é preciso refletir. Não podemos negar, porém, conforme a autora, que já houve bastante progresso nessa área de estudo, quando nos afastamos, por exemplo, da visão inicial teórica de uma "aplicação da Linguística", da busca por métodos eficazes (racionalidade técnica), evoluindo para a valorização de paradigmas crítico-reflexivos de pesquisa, e buscando a compreensão do papel do professor como um participante de seu próprio processo de desenvolvimento profissional.

Por isso, justifica-se a inegável contribuição do surgimento da prática exploratória, no âmbito da LA, enquanto forma inovadora de pesquisa do praticante, que

promove a integração das pessoas (professores, alunos e formadores de professores ou outros profissionais) e de suas atividades na busca de entendimentos aprofundados de suas questões da vida em sala de aula, na escola ou em outros contextos (MILLER, 2013, p. 111). 
Essa citação corrobora a necessidade de considerarmos, na contemporaneidade, a colaboração, a participação em conjunto de todos os envolvidos no processo de ensino aprendizagem e na investigação das práticas docentes, a qual possibilita a criação de reflexões teóricas. Isso não implica defender que todos compartilhem das mesmas ideias, mas sim que necessitam, de maneira integrada, refletir criticamente sobre a "inteligibilidade de problemas" (MOITA LOPES, 2006) emergentes e sociais, compartilhando seu sofrimento humano e profissional, enquanto produtores de conhecimento.

Por isso, compreender os três aspectos da linguagem(linguagem como/no/sobre trabalho), que constituem, genericamente, as práticas linguageiras na situação de trabalho e são elucidados por Nouroudine (2002), é fundamental para interpretarmos como a atividade, enquanto unidade de análise da Ergonomia, pode contribuir, significativamente, para o coletivo transformar-se e desenvolver-se profissionalmente, reconhecendo, inclusive, "os limites do invisível", uma vez que a linguagem se constitui como uma via de acesso à investigação do trabalho. Além disso, é importante, considerar a dupla complexidade constitutiva da linguagem e do trabalho - o caráter multidimensional e as propriedades múltiplas inerentes que se intercruzam -, que permite aproximá-los e, concomitantemente, revelar as especificidades de cada aspecto.

Tendo em vista o nosso objeto de estudo, analisamos o aspecto linguagem sobre trabalho, em que a linguagem é vista como instrumento de compreensão do agir, por isso, não é determinante presenciar a situação real, mas sim interpretar o que os trabalhadores dizem nos relatórios sobre a atividade realizada.

Esse tipo de análise tem muito a revelar, pois, como bem destaca Nouroudine (2002, p. 20), "seria ilusório acreditar que o recurso ao diálogo para exteriorizar a linguagem interior pudesse ter sucesso de forma mecânica", uma vez que "passa por um esforço necessário de distanciamento, de elaboração e de expressão". Esse aspecto se torna muito importante, pois permite a possibilidade de o agente falar e refletir sobre a atividade realizada e reconfigurar, a posteriori, sua própria prática, tendo em vista os impedimentos do contexto, os quais também são constitutivos da atividade e não devem ser enxergados apenas como erro, falha, mas como ponto de partida para uma prática reflexiva. 
v. 8 (3)

84-102

out-dez 2018

Logo, isso nos permite, também, analisar as reconfigurações sobre determinado agir docente. Conforme Bronckart (2007), para analisarmos as representações que socialmente se constroem sobre a ação docente, as quais podem se tornar representações individuais, devemos ter, como dados de análise, os textos (orais ou escritos), produzidos nos espaços educacionais. Tais textos configuram a rede discursiva que se constrói no e sobre o trabalho, e sua análise permite compreender a natureza, as razões das ações verbais e não verbais, bem como o papel desempenhado pela linguagem nesse contexto, ou seja, as (re)configurações construídas por meio dos mecanismos linguísticosdiscursivos e o desenvolvimento humano.

Os pressupostos da Psicologia vygotskyana destacam o desenvolvimento humano a partir da interação com o social. Essa evolução e apropriação dos pré-construídos, concomitantemente social e individual, permite conceber as ações linguageiras, as quais se tornam perceptíveis apenas pela observação do texto empírico. Tendo em vista algumas lacunas dessa teoria, o ISD se propôs justamente a isso: inscrever-se no esquema vygotskyano, integrando, porém, ao mesmo tempo, de maneira mais determinada, o papel e as propriedades da atividade de linguagem.

Nas palavras de Bronckart (2007, p. 116), o objetivo do ISD é

demonstrar o papel central da linguagem no conjunto dos aspectos do desenvolvimento humano e, consequentemente, seu papel nas orientações explicitamente dadas a esse desenvolvimento através das mediações educativas e/ou formativas.

Isto é, o ISD propõe uma teorização mais consistente sobre o papel da ação e da atividade humana para a construção da atividade de linguagem.

\section{Compreendendo as categorias da Semiologia do Agir}

De acordo com Rodrigues (2011, p. 132), "o agir humano nunca é diretamente observável, sendo as noções de ação, atividade, um produto de um processo interpretativo sobre as condutas diretamente observáveis". Isso quer dizer que, ao afirmarmos que estamos analisando o agir docente, na verdade, estamos interpretando o que os docentes dizem sobre suas ações, no que podem estar implicados fatores diversos. 
Nesse sentido, o ISD propõe a distinção entre ator, agente, ação e atividade:

O termo agir designa o dado sob análise, isto é, as diferentes ocorrências de intervenções de seres humanos no mundo, enquanto os termos atividade e ação designam interpretações desse agir, coletivas e individuais respectivamente, e que mobilizam ou explicitam as dimensões motivacionais e intencionais, assim como os recursos disponíveis para o agente (MACHADO, 2004, p. 154).

O termo "agir" se torna mais neutro, porque se refere ao "conjunto de condutas individuais, mediatizadas pela atividade coletiva de trabalho e dos seres que as realizam" (MACHADO; BRONCKART, 2009, p. 34). Assim, ao agente não são atribuídas as categorias da Semântica do Agir, pois ele não se implica, diferentemente do actante - qualquer pessoa implicada no agir. Já quando há uma interpretação do agir que atribua ao ator que se implica as razões, as intenções e os recursos, mobilizados por um coletivo organizado, temos uma atividade, ou, quando mobilizados por uma pessoa particular, uma ação.

O quadro, a seguir, sintetiza as categorias de uma Semântica do Agir e as dimensões que compõem cada plano:

Quadro 1: Elementos do Agir

\begin{tabular}{|l|l|l|l|}
\hline Razões & Intencionalidade & Recursos & Actantes \\
\hline $\begin{array}{l}\text { Determinantes } \\
\text { externos } \\
\text { Motivos }\end{array}$ & $\begin{array}{l}\text { Finalidades } \\
\text { Intenção }\end{array}$ & $\begin{array}{l}\text { Instrumentos } \\
\text { (recursos externos) } \\
\text { Capacidades } \\
\text { (recursos internos) }\end{array}$ & $\begin{array}{l}\text { Ator } \\
\text { Agente }\end{array}$ \\
\hline
\end{tabular}

Fonte: Próprio autor.

Primeiro, no plano motivacional, estão os determinantes externos, que podem ser de natureza coletiva, material ou da ordem das representações sociais, e os motivos, os quais constituem razões de agir interiorizadas por uma pessoa particular, mas que podem, no futuro, vir a ser guia para a coletividade. Depois, no plano da Intencionalidade, também se distinguem as finalidades, de origem coletiva e socialmente validadas, das intenções, interiorizadas por uma pessoa particular. Quanto aos recursos, temos os instrumentos, que podem ser ferramentas concretas ou modelos para o agir, disponíveis na sociedade, e as capacidades, que podem ser mentais ou comportamentais atribuídas a uma só pessoa. Por fim, os actantes, os quais se referem a qualquer pessoa implicada no agir, mas que, no plano da interpretação da ação ou atividade, quando a eles são atribuídas as dimensões elencadas, são denominados de ator, e quando não o são, de agente. 
V. 8 (3)

84-102

out-dez

2018

Além das dimensõescitadas, outrorecursoimportante, conforme Machado \& Bronckart (2009), para observar o agir representado, no que diz respeito aos critérios de verdade ou necessidade e às reações que geram nas instâncias enunciativas e nos tipos de interação estabelecidas entre os interactantes, é a análise das modalizações do enunciado.

As modalizações, segundo Bronckart (2012), configuram linguisticamente a avaliação do conteúdo temático e, conforme a função exercida, subdividem-se em quatro: modalizações lógicas, deônticas, pragmáticas e apreciativas. As modalizações lógicas, com base nas coordenadas do mundo objetivo, consistem em uma avaliação de alguns elementos do conteúdo temático, que são apresentados como fatos certos, possíveis, prováveis, improváveis, necessários etc. As modalizações deônticas avaliam, à luz das regras do mundo social, elementos do conteúdo temático, apresentando-os como socialmente, permitidos, proibidos, obrigatórios, desejáveis etc. As modalizações pragmáticas introduzem um julgamento sobre uma das facetas da responsabilidade de um personagem em relação ao processo de que é agente, e atribuem a esse agente intenções, razões, capacidade de ação. Já as modalidades apreciativas avaliam, conforme o mundo subjetivo, alguns aspectos do conteúdo temático, apresentando-os como benéficos, maus, estranhos, infelizes etc.

A fim de compreendermos, de maneira prática, essas dimensões, passemos à seção seguinte.

\section{Figuras interpretativas da ação docente detectadas em relatórios de Estágio Supervisionado em Língua Portuguesa}

Nesta seção, analisamos fragmentos de quatro relatórios (R1, R2, R3 e R4), considerando que as representações observadas nos textos, a partir das marcas linguísticas, fazem referência a três elementos do agir: razões, intencionalidades e recursos, em consonância com modalizações que indicam o posicionamento dos estagiários, frente ao conteúdo temático dos relatórios.

Um aspecto que se destacou nos relatórios foram os determinantes externos que interferiram, de algum modo, no agir do estagiário, como, por exemplo, a imposição dos professores-regentes responsáveis pelas turmas, o horário, as atividades extracurriculares, os imprevistos, conforme comprovado nos exemplos seguintes: 
R1 O grupo de profissionais como um todo e a direção da escola se mostram interessados com o ensino-aprendizagem dos alunos e levam meios inovadores para melhorar as práticas de ensino, no entanto nas aulas de língua portuguesa se limitavam ao uso do livro didático [...] o terceiro encontro de língua foi também de maneira tradicionalista devido às condições que me foram postas.

R1 Em conversa informal com a professora ficou acordado que não iríamos trabalhar com a sequência didática elaborada por mim -estagiária, pois a professora da turma precisaria cumprir com seu programa de aulas, no mais ela me passou os conteúdos e assim dei continuidade ao seu trabalho. [...] Diante do que foi concluído sobre a teoria, observamos, no período destinado à intervenção, que a prática se distancia dessa teoria adquirida, devido à realidade em que se encontraram as escolas neste período, especificamente, ou seja, se torna inviável, por exemplo, o uso de sequências didáticas elaboradas previamente sem antes uma consulta ao professor da escola escolhida para o estágio pra ter conhecimento sobre o que vai ser trabalhado em sala naquele período, além disto, é preciso acompanhar os métodos do professor em sala de aula quando não nos épermitido atuar livremente na sala de aula de outro profissional. [...] Ainda neste sentido existe o que poderíamos chamar de "frustração" por parte do discente que deseja sair do centro acadêmico para aplicar as teorias adquiridas (grifos nossos).

No trecho de R1, fica visível a imposição do professor responsável para o estagiário seguir o percurso já traçado para "cumprir seu programa de aulas" e "as condições postas", enquanto fatores externos que interferem na execução da sequência didática planejada pelo estagiário. Além disso, R1 destaca que os recursos utilizados nessa escola se limitam ao uso do livro didático, tornando a aula "tradicionalista" (no entanto nas aulas de língua portuguesa se limitavam ao uso do livro didático). Diante desse contexto, percebemos o uso da modalização apreciativa, por parte do autor, ao avaliar sua experiência na seguinte passagem: "neste sentido existe o que poderíamos chamar de "frustração" por parte do discente que deseja sair do centro acadêmico para aplicar as teorias adquiridas". 
v. $8(3)$

84-102

out-dez

2018

Para reforçar tal fato, ainda observamos o uso da modalidade pragmática, para reforçar que "é preciso 1 acompanhar os métodos do professor em sala de aula quando não nos é permitido atuar livremente na sala de aula de outro profissional", ou seja, o estagiário defende que é necessário conhecer o contexto de trabalho, pois não se trata de, meramente, chegar em uma sala de aula, desconhecendo a realidade dos alunos, e seguir o proposto pelo professor titular. Observamos uma capacidade crítica por parte desse estagiário, que demonstra já ter uma inserção profissional, inclusive, considerando-se um integrante da classe de professores e, não somente, um estagiário, quando afirma "na sala de outro profissional".

Esse fator da frustração pode interferir, de algum modo, no desenvolvimento da construção identitária de licenciandos em formação inicial, na fase de estágio, devido à rejeição do professor titular da turma, quando esse considera o estagiário um intruso em seu território e não alguém que pode contribuir para melhorar sua prática pedagógica. Isso pode desmotivá-los ou até mesmo negar totalmente a oportunidade para que exerçam a docência autônoma e passem a ser obrigados a seguir, apenas, o que for prescrito pelo professor titular.

R2 Infelizmente por conta do horário a aula não pode ser concluída. As atividades de reescrita e análise foram propostas porém não terminadas naquele momento. O mesmo ocorreu na turma 3D. A atividade de refacção coletiva foi proposta porém não finalizada por conta do horário.

R3 No nosso segundo dia de aula relembramos a proposta feita aos alunos na aula anterior sobre a produção textual que eles fariam e posteriormente iniciamos o trabalho com o gênero propaganda de cosméticos. [...] O quarto dia de aula levamos revistas para que os alunos iniciassem as suas produções textuais. Como ocorreu um problema/imprevisto no que diz respeito à apropriação das revistas de cosméticos, tivemos que trabalhar com a propaganda num geral, e não só a de

\footnotetext{
${ }^{1}$ Vale destacar que, embora a expressão "é preciso" pareça indicar que a modalidade seja considerada deôntica, entendemos se tratar, neste caso, de uma necessidade (de um poder fazer, querer fazer, como situa Bronckart (1999), ao descrever as características vinculadas às modalizações) relacionada ao uso situado, que é condicionada por uma restrição específica: a impossibilidade de atuar com liberdade na sala de outro professor, por estar na condição de estagiário. Logo, não se trata de uma obrigatoriedade determinada, de um dever situado. Isso denota uma certa instabilidade quanto à classificação das modalizações, já que, a depender do contexto, dos interlocutores envolvidos, pode haver uma certa oscilação entre uma modalização pragmática e deôntica.
} 


\section{cosméticos.}

Quanto a R2 e R3, também visualizamos fatores externos que intervêm na ação do estagiário - "horário" e "problema/imprevisto" -, assim como os recursos utilizados: "atividades de reescrita coletiva" e "revistas para produção textual". Um fato que se torna marcante em R3 e que representa a realidade da prática docente, diante de situações inusitadas que configuram o trabalho realizado, é a renormalização, quando, perante um impedimento do planejado (Como ocorreu um problema/imprevisto no que diz respeito à apropriação das revistas de cosméticos), o estagiário resolve com outra estratégia (tivemos que trabalhar com a propaganda num geral, e não só a de cosméticos), o que se torna claro, também, pelo uso da modalização pragmática, por meio da qual o autor assume a responsabilidade da ação, tendo em vista o que seria possível fazer, denotando um tom de justificativa do ocorrido. Isso não é negativo no percurso do estágio docente, pois, assim, o estágio permite a interiorização de que nem sempre vai ser possível agir tal qual se planeja e, portanto, o professor deve estar preparado para um "plano B".

R4 Em seguida nos foi dada a autorização para que pudéssemos ministrar a $1^{\mathrm{a}}$ aula na qual iria ser trabalhada "a tipologia textual dissertativo argumentativo", tipologia essa escolhida a fim de apresentar a redação exigida pelo ENEM visto que os alunos estavam na reta final do ensino médio e esses estariam almejando uma vaga nas universidades.

\section{[...]}

Após corrigido o questionário, C. R., professor titular daquela turma tinha anteriormente solicitado que terminássemos $\mathrm{o}$ exercício para o mesmo poder liberar os alunos, a fim de assistirem uma homenagem que seria feita a um professor de geografia que tinha falecido na segunda feira e a escola juntamente com todo o corpo discente e administrativo iria fazer essa homenagem.

\section{[...]}

Depois da análise coletiva solicitamos aos alunos que reescrevessem textos observando as anotações feitas por nós estagiários e que acrescentasse o que conviesse a cada um [...] Lembrando que as reescritas deveriam ser entregues novamente aos estagiários e esses iriam corrigir novamente e a pedido do professor repassamos as mesmas para que ele 
v. 8 (3)

84-102

out-dez

2018

\section{adotasse com critério de avaliação do 3 bimestre.}

Dentre os relatórios analisados, percebemos que em $\mathrm{R} /$, fica mais explícita, por meio de diversos exemplos a interferência de fatores externos na ação do estagiário, deixando transparecer, inclusive, uma falta de autonomia por parte deste. Isso inicia desde a "autorização" para ministrar a primeira aula, até a interferência de outro fator que é a política do Exame Nacional de Ensino Médio (ENEM), que direciona o trabalho com "a tipologia textual dissertativo argumentativo".

Depois, devido a uma atividade extracurricular (homenagem a um professor de Geografia que havia falecido), a dupla de estagiários é solicitada a liberar a turma; e, além disso, em outro momento "a pedido do professor", as reescritas orientadas pelos estagiários devem ser entregues ao professor titular, para que possa constituir uma nota do bimestre.

Conforme observamos, o tom prescritivo do professor titular com os estagiários é modalizado: "para poder liberar; a pedido"; mesmo assim, comprovamos a hierarquia intrínseca a essa relação, a qual se torna um problema quando há abuso do nível de poder.

Sabemos também que, embora o método de avaliar seja importante para o estagiário, talvez ainda não seja o momento de sua avaliação constituir uma nota para avaliação bimestral do aluno, tendo em vista que, muitas vezes, essa é a experiência primeira de muitos estagiários, que ainda estão se apropriando do agir docente e constituindo sua identidade profissional. Isso é comprovado pela afirmação, presente no exemplo seguinte, em que se diz considerar importante até a maneira de se "comportar perante as aplicações de atividade de verificação da aprendizagem".

R4 Na segunda aula, o professor solicitou que nessa aula deixasse para aplicar uma tarefa avaliativa com o objetivo de fazer o fechamento do III bimestre. Portanto, a nossa contribuição foi ajudar o professor na aplicação dessa atividade. E, assim, nós podemos apreender como deve-se comportar perante as aplicações de atividade de verificação da aprendizagem.

Prosseguindo na análise das categorias do agir, no que se refere à intencionalidade, visualizamo-la mais em nível de finalidade do que intenções, tendo em vista que se destaca, nos relatórios, que, para determinados objetivos serem alcançados, quando se trata do contexto educacional, devemos considerar ações coletivas validadas socialmente, tomadas como necessárias. Isso justifica, possivelmente, o enlace do uso de modalizações 
deônticas, nos trechos seguintes, que reforçam a argumentação do que deve ser feito para que alcancemos determinada finalidade.

Corroborando isso, Nascimento (2010, p. 43) apresenta que

As investigações realizadas sobre a modalização deôntica têm revelado que esse tipo de modalização gera diferentes efeitos de sentido no enunciado e funciona como uma estratégia argumentativa que é utilizada para o locutor não só imprimir seu ponto de vista no enunciado, mas interagir com seu interlocutor indicando como espera que esse (re)aja a sua enunciação.

O trecho seguinte evidencia uma apreciação quanto à prática e aos recursos utilizados pela "maioria das escolas": leitura e produção de textos mecanizados. Consequentemente, apresentamos a modalidade apreciativa, por meio de uma avaliação subjetiva do que devemos fazer, para reverter esse quadro, conforme ilustra o excerto abaixo:

R1 Sabendo que existe uma grande falha na educação em relação aos seus trabalhos na maioria das escolas percebemos que elas continuam realizando seus trabalhos de leitura e produção de textos mecanizados. Para isso, será necessário propor novos métodos de ensino incluindo atividades de leitura com ênfase no papel do professor como incentivador da leitura por prazer, bem como dar oportunidade para os alunos produzirem textos cujo objetivo é que os mesmos tenham alguma finalidade dentro do meio social.

A finalidade apresentada em R2 também diz respeito ao conteúdo temático das atividades de leitura "para se tornarem leitores críticos e competentes" e o predomínio da modalização deôntica, atestando a obrigatoriedade do que deve ser feito, no coletivo, "os educandos devem ter contato/acesso com os mais diversos tipos de gêneros textuais, e a partir disso desenvolverem o hábito da leitura com maior precisão; As atividades de leitura devem levar o aluno [...]".

Observamos, ainda, em tom argumentativo, o uso da modalidade apreciativa, relacionada ao campo do que podemos fazer para atingir a finalidade elucidada: "Se faz necessário apenas algumas práticas educativas de qualidade [...] "É possível realizar vários tipos de propostas que pressupõem a participação ativa do aluno [...]". 
v. 8 (3)

84-102

out-dez

2018

R2 Assim para se tornarem leitores críticos e competentes, os educandos devem ter contato/acesso com os mais diversos tipos de gêneros textuais, e a partir disso desenvolverem o hábito da leitura com maior precisão. As atividades de leitura devem levar o aluno a perceber as variações/alterações que cada gênero abarca consigo, dessa forma a possibilidade de relacioná-los e identifica-los com alguma produção escrita posterior será de grande relevância $[\ldots]$ Se faz necessário apenas algumas práticas educativas de qualidade para que essas temáticas possam realmente ser aplicadas de formas favoráveis a apreciação dos segmentos em questão. É possível realizar vários tipos de propostas que pressupõem a participação ativa do aluno e não se limitar apenas aos aspectos intelectuais ou a memorização de conteúdos julgados como relevantes.

Em R3, embora as modalizações deônticas também estejam aliadas à finalidade, o conteúdo temático volta-se para o posicionamento sobre a prática do estágio e o trabalho com a gramática normativa.

R3 Não basta elaborar um plano de aula "perfeito" e acreditar que ele contribui tanto para o acadêmico quanto para os alunos de ensino fundamental e médio. Como percebemos, reflexões precisam ser instauradas, para que os estágios possam garantir uma significativa prática pedagógica, de forma que os saberes escolares e os acadêmicos circulem em ambas as instituições. Entretanto, não basta apenas a interação mútua, é claro que o formador precisa ser responsável pela reflexão acerca da sua disciplina.

$[\ldots]$

A atividade trouxe significativa contribuição profissional/ acadêmica por nos sensibilizar mostrando a importância da humanização durante o estágio; nos mostrou as várias identidades que o professor deve assumir para lidar com os alunos.

$$
\text { [...] }
$$

É necessário que nós professores de Língua Portuguesa ao trabalharmos a gramática normativa nos atentemos 
e observemos o funcionamento da língua, para que não imponhamos em nossos alunos regras rígidas e arbitrárias de maneira abrupta e descontextualizada do sistema linguístico que se organiza do lado de fora da escola (na vida real do aluno), a fim de lhe oferecer todo o repertório necessário para se expressar nas diversas situações discursivas.

No primeiro momento, a finalidade sobre a qual o autor de R3 reflete é: "para que os estágios possam garantir uma significativa prática pedagógica, de forma que os saberes escolares e os acadêmicos circulem em ambas as instituições". Em seguida, vale-se de modalizações deônticas, para defender o que deve ser feito: "reflexões precisam ser instauradas; o formador precisa ser responsável pela reflexão acerca da sua disciplina".

Ainda quanto à avaliação do estágio, temos uma modalização pragmática - "A atividade trouxe significativa contribuição profissional/ acadêmica" - aliada a uma modalização deôntica, que justifica sua avaliação, bem como colabora para a percepção de sua atuação, enquanto futuro docente: "nos mostrou as várias identidades que o professor deve assumir para lidar com os alunos".

Outra reflexão importante feita em $\mathrm{R} 3$ diz respeito à finalidade da abordagem da gramática normativa em sala de aula, "para que não imponhamos em nossos alunos regras rígidas e arbitrárias de maneira abrupta e descontextualizada do sistema linguístico que se organiza do lado de fora da escola (na vida real do aluno)" e a modalidade deôntica: "É necessário que nós professores de Língua Portuguesa ao trabalharmos a gramática normativa nos atentemos e observemos o funcionamento da língua". Aqui, percebemos que a modalização é acionada para retomar um juízo de valor relacionado ao ensino de gramática contextualizado que é pressuposto pelo autor como compreensível e aceito por todos os professores.

Para finalizar a análise sobre a categoria finalidade, observemos R4:

$\mathbf{R} 4$ Deve-se aprender na prática aquilo que nos foi repassado durante vários semestres dentro das salas de aula da universidade bem como podemos ainda aprender que há uma distância entre o que é idealizado e do que é posto em prática, mas tudo isso se deve ao nosso esforço para pudermos repassar aos nossos alunos. [...] Para que isso aconteça, é necessário determinação para recomeçar quando tudo parece estar perdido seja para o docente, seja para o discente. 
v. $8(3)$

84-102

out-dez

2018

Em R4, embora tenhamos uma modalidade pragmática, "podemos ainda aprender que há uma distância entre o que é idealizado e do que é posto em prática", visualizamos o entrelaçamento entre a finalidade e a modalidade deôntica, em que esta se torna condição para aquela, pois o autor reforça que, para alcançar a finalidade, "Devese aprender na prática aquilo que nos foi repassado durante vários semestres dentro das salas de aula da universidade", mas destaca que, "Para que isso aconteça", "é necessário determinação para recomeçar quando tudo parece estar perdido seja para o docente, seja para o discente". Portanto, a modalidade deôntica reforça, mais uma vez, a argumentação da necessidade da determinação.

\section{Considerações finais}

Recuperando o objetivo proposto para este estudo - analisar as categorias da Semiologia/Semântica do Agir, tematizadas em relatórios de Estágio Supervisionado de formação inicial em Língua Portuguesa e seu entrelaçamento com as modalizações -, pudemos constatar que houve, nos relatórios analisados, o uso de modalidades pragmáticas, apreciativas e deônticas aliadas à categoria do agir finalidades, atribuindo um caráter argumentativo, partindo-se de uma avaliação subjetiva do professor em formação inicial e visando à adesão da coletividade, em relação ao que deve ser realizado para reverter algumas práticas de atividades de leitura e escrita, que se restringem ao uso do livro didático, a aulas mecanizadas e tradicionalistas.

Em consonância com essas modalizações, as representações observadas nos relatórios, a partir das marcas linguísticas, fazem referênciaatrêscategorias da SemânticadoAgir:razões, intencionalidades e recursos. Um aspecto que se destacou, interferindo, de algum modo, e configurando as razões do agir dos estagiários foram os determinantes externos, a exemplo da imposição dos professores-regentes responsáveis pelas turmas, do horário e das atividades extracurriculares.

No que se refere à intencionalidade, visualizamo-la mais em nível de finalidade do que intenções, tendo em vista que se destaca, nos relatórios, nos quais consta que, para determinados objetivos serem alcançados, quando se trata do contexto educacional, devemos considerar ações coletivas validadas socialmente, tomadas como necessárias.

Quanto ao papel assumido pelos estagiários, embora assumam a responsabilidade na condução da aula, em sua maior parte, não 
aparecem efetivamente como atores, devido a fatores externos, como a imposição do professor titular da turma, que aparentam demarcar uma relação hierárquica de superioridade. Isso demonstra a necessidade de cumplicidade que deve haver entre professor-estagiário/ professor titular e professor coordenador da disciplina de Estágio.

Mesmo assim, percebemos que a prática do ES é de extrema valia para os estagiários iniciantes, os quais estão se apropriando do gênero da atividade e constituindo sua identidade profissional, para que possam conhecer de perto a realidade das escolas, onde poderão atuar futuramente e refletir criticamente sobre os recursos utilizados, sobre as necessárias renormalizações e, até, para refletir sobre o profissional que não desejam ser.

\section{Referências}

AMIGUES, R. Trabalho do professor e trabalho de ensino. In: MACHADO. A. R. $\mathbf{0}$ ensino como trabalho: uma abordagem discursiva. Londrina: Eduel, 2004. p. 35-53.

BELTRÃO, O.; BELTRÃO, M. Correspondência: linguagem e comunicação oficial, comercial, bancária e particular. 20 ed. São Paulo: Atlas, 1998.

BRONCKART, J. P. Atividade de linguagem, textos e discursos: por um 101 interacionismo sócio-discursivo. Tradução Anna Rachel Machado. 2. ed. São Paulo, EDUC, 2012.

. Atividade de linguagem em relação à língua - homenagem à Ferdinand de Saussure. In: GUIMARÃES, A. M. M; MACHADO, A. R.; COUTINHO, A. (Orgs.). $\mathbf{O}$ interacionismo sociodiscursivo. Campinas, SP: Mercado de Letras, 2007.

Atividade de linguagem, discurso e desenvolvimento humano. Campinas, SP: Mercado de Letras, 2006.

0 agir nos discursos: das concepções teóricas às concepções dos trabalhadores. Campinas: Mercado das Letras, 2008.

CLOT, Y. A função psicológica do trabalho. 2. ed. Petrópolis: Vozes, 2007.

LEURQUIN, E. V. L. F. O gênero acadêmico relatório na formação inicial do professor de língua materna. In: BUENO, L., LOPES, M. A. P. T., CRISTOVÃO, V. L. L. (Orgs.). Gêneros textuais e formação inicial: uma homenagem à Malu Matêncio. Campinas: Mercado de Letras, 2013. p. 281-299

MACHADO, A. R. o ensino como trabalho: Uma abordagem discursiva. Londrina: Eduel, 2004.

MACHADO, A. R.; BRONCKART, J.P. (Re-)configurações do trabalho do professor construídas nos e pelos textos: a perspectiva metodológica do Grupo ALTERLAEL. In: MACHADO, A. R. et. al. Linguagem e Educação: 0 trabalho do professor em uma nova perspectiva. ABREU-TARDELLI, L. S.; CRISTOVÃO, V. L. L. (Orgs). Campinas: Mercado de Letras, 2009. p. 31-77. 
v. $8(3)$

84-102

out-dez

2018

MEDRADO, B. P. Tornando-se professor: a compreensão de graduandos em Letras sobre a atividade educacional. In: MEDRADO. B. P., REICHMANN, C. L. (Orgs.) Projetos e práticas na formação de professores de Língua Inglesa. João Pessoa: Editora Universitária da UFPB, 2012. p. 151-169.

MENEZES, R.L. C. de.; MEDRADO, B. P. Formação em psicologia clínica: o estágio supervisionado como atividade potencial de desenvolvimento profissional. InterScientia, João Pessoa, v. 1, n. 2, p. 37-51, maio/ago. 2013.

MILLER, I. K. Formação de professores de línguas: da eficiência à reflexão crítica e ética. In: LOPES, L. P. da M. (Org.). Linguística Aplicada na modernidade recente: festschrift para Antonieta Celani. São Paulo: Parábola, 2013. p. 99121.

MIRANDA, M. I. Ensino e pesquisa: o estágio como espaço de articulação. In: SILVA, L. C.; MIRANDA, M. I. 0 estágio supervisionado e prática de ensino: desafios e possibilidades. Araraquara: Junqueira \& Marin - Belo Horizonte: FAPEMIG, 2008.

MOITA LOPES, L. P. (Org.). Por uma Linguística Aplicada Indisciplinar. São Paulo: Parábola Editorial, 2006. 279p.

NASCIMENTO, E. A modalização deôntica e suas peculiaridades semânticopragmáticas. Fórum Linguístico, Florianópolis, v. 7, n. 1, p. 30-45, jan-jun, 2010.

NOUROUDINE, A. A linguagem: dispositivo revelador da complexidade do trabalho. In: SOUZA-E-SILVA, M. C. P.; FAÏTA, D. (Orgs.). Linguagem e Trabalho: construção de objetos de análise no Brasil e na França. São Paulo: Cortez Editora, 2002. p. 17-30.

RODRIGUES, M. A. N. As (re)configurações sobre o trabalho docente em relatórios de estágio. 2011. $216 \mathrm{f}$. Tese (Doutorado em Linguística) - Programa de Pós-Graduação em Linguística, Universidade Federal da Paraíba, João Pessoa, 2011.

PIMENTA, S. G; LIMA, M. S. L. Estágio e docência. 3. ed. São Paulo: Cortez, 2008.

TELLES, J. "É pesquisa, é? Ah, não quero, não, bem!" Sobre pesquisa acadêmica e sua relação com a prática do professor de línguas. Linguagem e Ensino. v. 5, n. 2, p. 91-116, 2002. 